\title{
A prática da formatura na educação superior: apontamentos para uma reflexão
}

Ediana Abreu Avelar Mestre em Educação - UCP; Graduada em Comunicação Social - Facha; Coordenadora do Curso de Publicidade da Universidade Veiga de Almeida (UVA); Professora-substituta da ECO/ UFRJ; Pesquisadora do GT Ideário Republicano PROPED/UERJ.

Rio de Janeiro - RJ [Brasil] ediana@uva.br
Neste estudo, tenciona-se identificar e analisar o sentido do rito da colação de grau no ensino superior, cuja significação permanece inalterada desde a sua institucionalização. Nesta investigação descreve-se a acepção das formaturas atuais para destacar a realização desse ato institucional cujos aspectos se realizam, repetidamente, de modo acrítico. A outorga do grau é uma ação obrigatória para os concluintes da educação superior, mas os arranjos festivos para a realização da formatura solene deslocam a atenção dos sujeitos participantes, levando-os a uma representação alienada de pouco controle nos espaços acadêmicos.

Palavras-chave: Educação. Formatura. Imaginário. 


\section{Introdução}

Este ensaio é resultado da pesquisa "O imaginário da formatura: um estudo sobre o pensamento dos formandos de Direito pertencentes à classe média", defendida no programa de mestrado da Universidade Católica de Petrópolis, em maio de 2007. O ineditismo desse estudo vem abrindo espaço para um diálogo mais crítico acerca da prática das formaturas contemporâneas e da organização de seus cerimoniais, de modo que, em breve, será possível a realização de solenidades mais conscientes e ajustadas tendo como base as intenções educacionais, pois como afirma Pinto

[...] para além das ideologias pedagógicas e das transformações institucionais, é necessário que também se tomem as práticas acadêmicas como objeto de análise, pois a dimensão prática revela o sistema de valores e representações que, apesar de encoberto pelo discurso oficial, permanece atuante entre os agentes, sem que seja alvo de uma sistematização consciente. (1999, p. 16).

Pode parecer, em um primeiro momento, que a questão do sonho de ingresso em um curso universitário e, conseqüentemente, da cerimônia da formatura, esteja ultrapassada e banalizada perante a ótica urbana, para a qual rotinas e práticas tradicionais fazem parte de um contexto comum em razão da assiduidade de sua realização. Entretanto, costumeiramente, não é o que se vislumbra nos palcos das instituições de ensino superior e nos anfiteatros dos clubes sociais, principalmente para os alunos universitários oriundos das classes intermediárias que, pela força de suas heranças histórico-culturais, fazem da conquista do diploma universitário e da participação na formatura um objeto de desejo, não só em razão dos benefícios profissionais que esse estado the confere, mas também pela imagem simbólica que esse novo status garante às identidades desses sujeitos.

Muito mais do que uma reflexão, este estudo tem o compromisso de trazer a relevo um tema adormecido nas pesquisas sobre práticas escolares, cujo objetivo é promover um debate sobre novas indagações que permitam prováveis conjecturas, ações e reações, se não mais eficazes, pelo menos, mais críticas a respeito dos rituais nas instituições de ensino superior.

Dada sua centenária instituição em nosso país, a formatura merece um olhar que procure, mais do que observar e descrever, anunciar seus efeitos, não só para os atores diretos e indiretos do objeto, tais como formandos, familiares e homenageados, mas também e, principalmente, para os organismos envolvidos com as práticas educacionais.

\section{Aspectos das formaturas contemporâneas}

A formatura universitária é uma ação social significativa, especialmente para os formandos e seus familiares. Embora seja um ato oficial da faculdade, é estimulada, principalmente, por elementos subjetivos, tais como a tradição e os apelos comerciais. Apesar de ter sido instituída há décadas, seu ritual permanece inalterado em diversos aspectos. Consolidada nas rotinas escolares, seu acontecimento não demanda muita atenção dos setores acadêmico-administrativos, sendo percebida até com certa banalização. Inserida na cultura organizacional da escola, ela faz parte de um cotidiano diversificado e dinâmico e, muitas vezes, sua ocorrência não se dá 
de forma crítica. Pode ser considerada parte de uma estrutura escolar, entendida, segundo Nóvoa, como "[...] composta por elementos vários, que condicionam tanto a sua configuração interna, como o estilo de interações que estabelece com a comunidade." (1995, p. 30).

Nessa perspectiva, pode-se categorizar a formatura como um elemento contido na Zona de Visibilidade $^{1}$, manifestado, sobretudo, nos rituais e cerimônias arranjados pelos agentes da organização, chamados por Nóvoa de "Manifestações comportamentais":

Incluem-se todos os elementos susceptíveis de influenciar o comportamento dos actores da organização. Referimo-nos, por um lado, às actividades normais da escola a ao modo como são desempenhadas (prática pedagógica, avaliações, exames, reuniões de professores, escolha da direcção, etc.) e, por outro lado, ao conjunto de normas e de regulamentos que as orientam, bem como aos procedimentos operacionais impostos ou assumidos pelos membros da organização. Situa-se também nessa categoria a série de rituais e de cerimoniais que fazem parte da vida organizacional: abertura do ano escolar, festas diversas, recepção aos caloiros, acolhimento dos novos professores, etc. Esta categoria remete fortemente para o nível de participação dos actores internos e externos - pais, autoridades locais, etc. na vida da escola. (1995, p.32).

Contudo, a análise da formatura como manifestação comportamental também permite incluí-la, em razão da pluralidade de seu significado, na Zona de Invisibilidade. No entanto, uma análise mais apurada de sua realização indica ser também um conjunto de elementos que

[...] integra os valores, as crenças e as ideologias dos membros da organização. Os valores permitem atribuir um significado às ações sociais e constituem um quadro de referência para as condutas individuais e para os comportamentos grupais. (NÓVOA, 1995, p.31).

Desse modo, percebemos no cotidiano universitário que, para alguns discentes, os ritos e os cerimoniais da diplomação se tornam ao final do curso, principalmente quando se aproximam os arranjos da formatura, mais importantes do que todo o programa curricular apreendido durante sua passagem pela universidade, o que nos leva a intuir e problematizar possíveis distorções e afastamentos dos principais objetivos educacionais: a transmissão do conteúdo e a formação do indivíduo.

Apesar de toda a emotividade e euforia que se entranham nas ações dos envolvidos com a chegada da formatura, existe uma tensão ao se perceber que os valores gastos na solenidade da colação de grau, segundo dados da pesquisa, superam muitas vezes os valores investidos em livros e informações essenciais para o aprendizado.

Há dissonância nos espaços acadêmicos quando se vê, pelos corredores das faculdades, a panfletagem de várias empresas de formatura comercializando símbolos e preparativos para cerimoniais, além do assédio sorrateiro aos alunos. Ações cotidianas que nos levam a sugerir que existe rara reflexão a respeito dessa prática por parte dos agentes envolvidos com o ensino superior. 


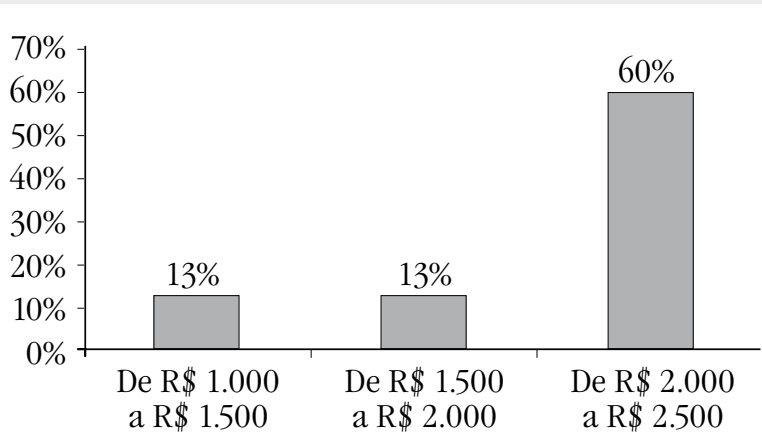

Gráfico 1: Valores gastos na formatura

Fonte: Dados da Pesquisa - Identificação dos valores monetários gastos em uma formatura do ensino superior em novembro de 2006.

Em comparação com outros rituais acadêmicos instituídos, fica visível a falta de controle institucional, como nos sugere Severino (apud ZUIN, 2002, p. 11), referindo-se aos trotes nas instituições de ensino superior:

A comunidade universitária, os responsáveis pela condução do sistema educacional do país e a própria sociedade parecem preferir eximir-se de uma discussão mais competente e consciente com pessoas e grupos envolvidos na educação sobre a real natureza do trote. Adotam a postura da avestruz frente ao problema, como se ele não existisse, não se dando conta de que o processo educativo precisa partir das questões antropológicas de fundo. A educação não existe apenas para reproduzir andróides, mas sobretudo para construir, historicamente, a espécie humana.

Dessa forma, tal como os trotes nas faculdades, mas sem o tom da barbárie de alguns casos em seu contexto, as formaturas contemporâneas dos cursos universitários se realizam de modo acrítico e automático, pois são geralmente conduzidas pela convenção instituída na sociedade histórica, núcleo central do imaginário social e do fazer humano. Como nos diz Castoriadis,

[...] Todo pensamento da sociedade e da história pertence em si mesmo à sociedade e à história. Todo pensamento, qualquer que seja ele e qualquer que seja seu "objeto", é apenas um modo e uma forma do fazer social-histórico. Pode ignorar-se como tal - e é o que lhe acontece mais freqüentemente por necessidade, por assim dizer, interna. E o fato de conhecer-se como tal não o faz sair de seu modo de ser, como dimensão do fazer social-histórico. [...] A história é essencialmente poiésis, e não poesia imitativa, mas criação e gênese ontológica no e pelo fazer e o representar/dizer dos homens. Este fazer e este representar/dizer se instituem também historicamente, a partir de um momento, como fazer pensante ou pensamento se fazendo. (1982, p. 13-14).

Além disso, os resquícios do caráter formalista brasileiro e os argumentos persuasivos do mercado de formaturas reforçam e realçam a importância e o valor simbólico desses procedimentos.

[...] o indivíduo, por conseguinte, é ele próprio a criação deste mundo de significações e a socialização é o processo de aprendizagem, não apenas da linguagem e das instituições, mas de si mesmo como instituição criada pela sociedade à qual se pertence (AUGRAS, 2000, p. 128). 
Com relação à perpetuação das tradições, é notório que, nas últimas décadas, a sociedade contemporânea tenha fortalecido seu gosto pelo espetaculoso e pelos objetos que sugerem e imputam distinção às identidades pessoais. Além disso, as representações encarnadas nos acontecimentos da realidade sempre são acompanhadas de grande aparato teatral. Fascinada pelos efeitos dos fenômenos da espetacularização, a atenção dos indivíduos se volta para aquilo que garantirá glamour e sucesso, mesmo que seja de forma efêmera, como nos sugere Debord, ao se referir à sociedade do espetáculo:

Não é possível fazer uma oposição abstrata entre o espetáculo e a atividade social efetiva: esse desdobramento também é desdobrado. o espetáculo que inverte o real é efetivamente um produto. Ao mesmo tempo, a realidade vivida é materialmente invadida pela contemplação do espetáculo e retoma em si a ordem espetacular à qual adere de forma positiva. A realidade objetiva está presente dos dois lados. Assim estabelecida, cada noção só se fundamenta em sua passagem para o oposto: a realidade surge no espetáculo, e o espetáculo é real. Essa alienação recíproca é a essência e a base da sociedade existente. (DEBORD, 1997, p. 15).

Muito embora a solenidade de formatura seja mais um produto de consumo, mais uma representação espetaculosa do que uma necessidade, não se pode negar que sua realização gera, nos atores envolvidos, uma verdadeira satisfação.

\section{A tradição da colação de grau no ensino superior}

Todo aluno de cursos de graduação que termine os créditos de sua matriz curricular com o aproveitamento exigido deve ter o seu grau concedido por um ato oficial acadêmico-administrativo, solene ou não. Segundo a recomendação do Manual da Solenidade de Colação de Grau dos alunos de graduação das Faculdades UNICEN - uma rara iniciativa no universo das instituições de ensino superior) - a formatura é concebida como "[...] um momento único, especial e por isso deve ser vivido e comemorado com intensidade." (s/ data, p. 2).

A colação de grau é, tradicionalmente, um ato obrigatório para a emissão e registro do diploma e não pode ser dispensada que seja a qualquer alegação, conforme o Parecer 783, aprovado em 8 de novembro de 1971 pela C.E.Su.(Comissão de Ensino Superior):

Quanto aos termos, esclarecemos que é livre a apresentação dos diplomas - formato e conteúdo - embora deles não possam deixar de constar o título conferido e, quando o curso abranger mais de uma habilitação (como Pedagogia e Letras, por exemplo), a habilitação (ou as habilitações) que o diplomado realmente obteve. Aliás, nesta última hipótese, aconselha-se que o diploma contenha no anverso apenas o título geral de graduação e no verso as habilitações. Desta forma, as novas habilitações que o seu portador venha a obter, mediante volta à escola, poderão ser igualmente lançadas no verso, evitando-se o absurdo de que mais de um diploma seja expedido para o que em rigor é um só curso. Observe-se ainda que nas universidades, conforme dispõe o art. 8. $^{\circ}, \S$ 
3. ${ }^{\circ}$, do Decreto-Lei no. 252/67, "o título será sempre conferido" e o diploma assinado pelo Reitor, e não pelo Chefe do Departamento. (1971, p. 265 - grifo nosso).

Portanto, a imposição do grau pode ser de forma simples, em uma sala ou em um gabinete departamental, e concedido por alguém credenciado pela reitoria para essa finalidade. De outra forma, dada a valorização que a sociedade atribui a essa titulação, pode-se outorgar o grau de bacharel ou de licenciado em cerimônia pomposa, o que acaba por gerar um protocolo exclusivo e uma gama enorme de procedimentos, aparatos festivos e muitos gastos financeiros.

De modo geral, o significado do título da graduação universitária está imbuído de fortes valores que extrapolam as projeções do próprio formando e, muitas vezes, transcendem e impregnam todos os entes de uma mesma família. Os indícios do novo status e da mobilidade social são ardorosamente almejados, pois fazem parte de um elenco de signos que corroboram o cenário ritualístico da ascensão social. A cerimônia da colação de grau, o convite de madeira encamurçado, a beca, o anel, o tão desejado canudo, discursos e homenagens, além da imagem fotográfica, na qual o formando se ostenta paramentado, são os registros memoráveis de um tipo de capital cultural alcançado, como indica a nota publicada no jornal Correio da Bahia:

Sabedora da morte certa, ela não pedia muito. Era católica fervorosa - Deus haveria de atender sua maior vontade (sic), dandolhe mais alguns meses de vida. Bastava o suficiente para assistir ao neto se formar em medicina. Na vida de uma velha pobre e semi-analfabeta, não poderia haver orgulho maior do que ver brilhar, no dedo do neto, um bonito anel de doutor. (CORREIO DA BAHIA, 7 maio 2004).

Uma tensão que se apresenta freqüentemente e que vem fugindo ao controle institucional é o envolvimento na solenidade de formatura de alunos que não fecharam seus créditos. Essa situação ocorre estimulada por diversos motivos, tais como afinidade com a turma de origem, expectativa familiar ou facilidade normativa na própria instituição. Em razão desse contexto, muitos formandos não aptos à diplomação participam da solenidade de formatura apenas simbolicamente, não podendo prestar o juramento e receber a outorga. Todavia, essa concessão é um risco, pois abre vários precedentes àqueles que de 'má-fé', exigem na justiça, conforme apurado na pesquisa, a concessão do diploma de graduação. Seus documentos comprobatórios se pautam pela impressão do nome completo no convite, pela foto do pseudojuramento e na validação da cerimônia pela presença do colegiado acadêmico na solenidade que, na maioria das vezes, desconhece a situação acadêmica do aluno participante.

Outra situação equivocada refere-se aos alunos concluintes dos cursos seqüenciais de formação específica, autorizados em diversas instituições educacionais do país. Os egressos desses cursos não podem ter o grau outorgado e prestar o juramento próprio das categorias dos bacharéis ou licenciados, porque

\footnotetext{
[...] os cursos seqüenciais então não formam bacharéis, nem licenciados, nem tecnólogos, mas conferem competências acadêmicas e técnicas de nível superior aos portadores de seus diplomas e certificados, significando uma qualificação
} 
diferenciada. Em síntese: Cursos seqüenciais, embora de nível superior, não são cursos de graduação, ou seja, seus diplomas são diferentes dos diplomas e dos títulos obtidos nos cursos de graduação. (MARTINS, 2004, p.32).

No entanto, participar da solenidade, mesmo que de forma simbólica, junto aos colegas da turma e na presença dos familiares e amigos, é um momento de grande expectativa. Há uma ansiedade e um sonho por vestir uma beca, o capelo e a faixa; por receber, das mãos do presidente da cerimônia, um papel enrolado em uma fita que tão-somente será a representação solene de algo que não tem nenhum valor institucional, porém esperado pelo ideal imaginário.

\section{Considerações finais}

Não há como negar que a formatura é um ato instituído nas rotinas acadêmicas universitárias, e que, pelo valor atribuído a ela, torna-se um sonhado objeto de desejo, principalmente em razão dos valores de pertencimento produz em seus participantes. Para a maioria dos formandos, participar dessa prática no fim do curso simboliza a conquista de uma vitória no campo cultural, momento pessoal de realização. A posse desse título desperta sentimentos movidos por um imaginário que ainda considera essa conquista como um bem precioso, uma etapa concluída para o exercício de novas atividades profissionais e sociais.

Além disso, os arranjos e os objetos simbólicos de uma formatura trazem um tipo de linguagem invisível que revela uma cosmovisão produzida pelo imaginário dos sujeitos envolvidos no evento. Incrustado no inconsciente não revelado pela palavra, mas manifestado pela força de uma herança histórica, esse imaginário reproduz um passado que ecoa, apesar das distâncias temporais das gerações sociais.

A reprodução de certos comportamentos é, muitas vezes, reflexo de um imaginário que reside profundamente em nosso inconsciente. E, como a inconsciência é algo que está velado nossa consciência, é comum não nos darmos conta de que o nosso pensar e o nosso agir são influenciados por essa força-motora que nos é oculta, mas que se radica dentro de nós. O imaginário interfere em nossas intenções e decisões, e estar atento a ele, seja no plano individual ou coletivo, permite ações conduzidas por uma vontade mais consciente.

Mais que uma reprodução impulsionada pelas convenções históricas e/ou pelas persuasões mercadológicas, a colação de grau, em caráter solene, deve ser realizada de modo consciente, sobretudo pelos dirigentes universitários e orientadores pedagógicos que, com um olhar crítico, devem procurar abster-se da alienante cultura do espetáculo, para que a razão da educação seja, de fato, convalidada nesse ato e não se perca em meio às festas e ornamentações.

\section{The practice of the graduation ceremony in higher education: reflection on entries}

In this work, it is aimed to identify and analyze the meaning of the graduation ceremony in higher education, describing its current concept. In this research, it is considered the purpose of placing this practice in relief until nowadays and to study the reasons for its permanentness. The arrangement to its solemn accomplishment averts the attention of the attendees from the main target: the education.

Key words: Education. Graduation. Imaginary. 


\section{Nota}

1 Baseado no esquema de Hedley Beare (1989), Nóvoa sistematizou a cultura organizacional escolar em duas categorias: Zona de Invisibilidade, onde se encontram bases conceptuais e pressupostos invisíveis, tais como valores, crenças e ideologias, e a Zona de Visibilidade, onde se encontram manifestações verbais e conceptuais, manifestações visuais, simbólicas e comportamentais.

\section{Referências}

AUGRAS, Monique. Mil janelas: teóricos do imaginário. Psicologia Clínica Pós-graduação e Pesquisa, v.12, n. 1, p, 107-131, Rio de Janeiro, PUC, 2000.

BRASIL. Parecer n ${ }^{\circ} 783 / 71$, C.E.Su. (2. grupo). Diplomas de cursos superiores, conteúdo e registro. Aprovado em 8 de novembro de 1971.

CASTORIADIS, Cornelius. A instituição imaginária da sociedade. $5^{\text {a }}$ edição. São Paulo: Paz e Terra, 1982.
CORREIO DA BAHIA, Salvador. 17 maio 2004.

Disponível em: <http://www.correiodabahia.com.br $>$. Acesso em: 12 abr. 2005.

DEBORD, Guy. A sociedade do espetáculo. 7. ed. Rio de Janeiro: Contraponto, 1997.

MARTINS, Rubens de Oliveira. Cursos Seqüenciais: entendendo a formação superior de curta duração. 1. ed. Bauru: Edusc, 2004.

NÓVOA, António. As organizações escolares em análise. 2. ed. Lisboa: Publicações Dom Quixote, 1995.

PINTO, Gabriel Hilu da Rocha. Práticas acadêmicas e o ensino universitário. 1ª Ed. Niterói: EdUFF, 1999.

SEVERINO, Antonio J. Prefácio. In: ZUIN, Antonio A. S. (Org.) O trote na universidade: passagens de um rito de iniciação. 1. ed. São Paulo: Cortez, 2002.

UNICEN. Manual da solenidade de colação de grau dos alunos de graduação. Disponível em: <http:// www.unicem.edu.br/primavera/manual colação.pdf $>$. Acesso em: 18 ago. 2006.

ZUIN, Antonio A. S. O trote na universidade: passagens de um rito de iniciação. $1^{\mathrm{a}}$. Ed. São Paulo: Cortez, 2002. recebido em 18 jun. 2007 / aprovado em 9 ago. 2007

Para referenciar este texto:

AVELAR, E. A. A prática da formatura na educação superior: apontamentos para uma reflexão. Dialogia, São Paulo, v. 6, p. XX-XX, 2007.

Dialogia, São Paulo, v. 6, p. 149-156, 2007. 